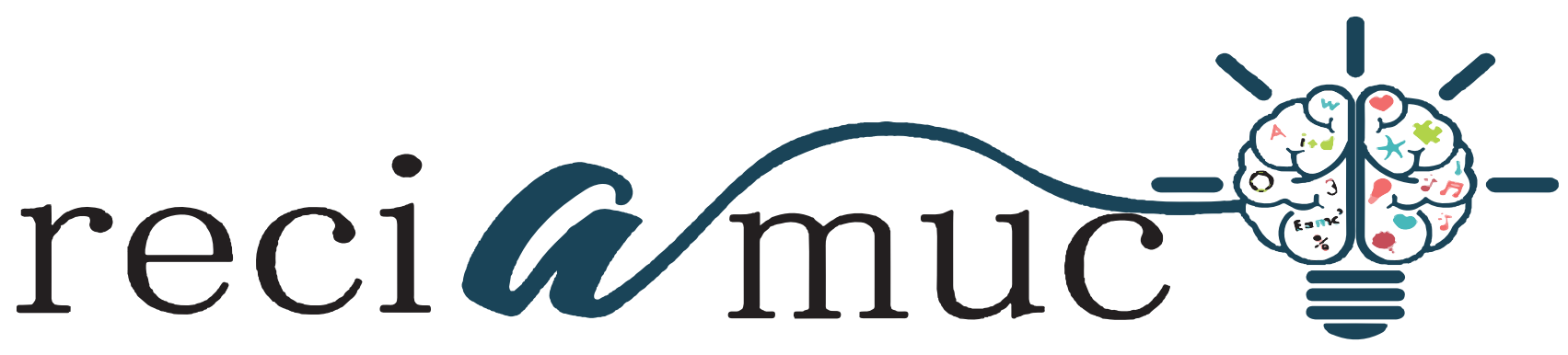

DOI: 10.26820/reciamuc/4.(3).julio.2020.208-215

URL: https://reciamuc.com/index.php/RECIAMUC/article/view/514

EDITORIAL: Saberes del Conocimiento

REVISTA: RECIAMUC

ISSN: 2588-0748

TIPO DE INVESTIGACIÓN: Artículo de Revisión

CóDIGo UNESCO: 32 Ciencias Médicas; 3201 Ciencias Clínicas

PAGINAS: $208-215$

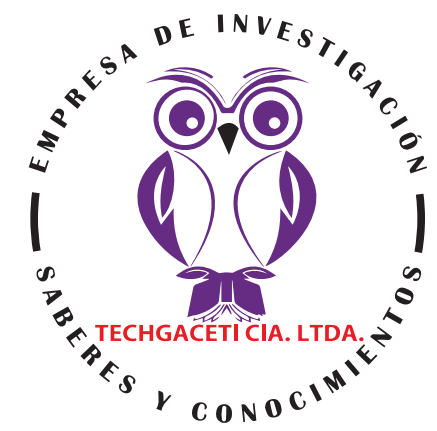

\title{
Utilidad de ecografía en drenaje percutáneo
}

Usefulness of ultrasound in percutaneous drainage

Utilidade do ultrassom na drenagem percutânea

\section{Darlys Tatiana Cerón Pérez'; Doménica Fernanda Báez Quiñónez²; Lizheth Catalina Álvarez Pérez; Dixon Marcelo Zambrano Palma ${ }^{4}$}

RECIBIDO: 20/05/2020 ACEPTADO: 19/07/2020 PUBLICADO: 30/07/2020

1. Médica asistencial UCl adultos - Esp. gerencia de la calidad y auditoría en Salud; Popayán-Cauca, Colombia; taticeron18@ gmail.com; (iD https://orcid.org/0000-0001-8454-0968

2. Medica residente en el Hospital de Especialidades Carlos Andrade Marín en el servicio de Coloproctologia; Quito, Ecuador; dome_baezlsffs@hotmail.com; (D) https://orcid.org/0000-0002-5332-3001

3. Médico Residente en Funciones Hospitalarias. Magíster en Seguridad y Salud Ocupacional y Prevención de Riesgos Laborales; Riobamba, Ecuador; lizz_-kata11@hotmail.com; iD https://orcid.org/0000-0003-2723-2330

4. Médico Residente en hospital General docente de Calderón; Ecuador, Quito; dixon_zambrano2289@outlook.es; (DD https:// orcid.org/0000-0001-9935-7103

CORRESPONDENCIA

Darlys Tatiana Cerón Pérez

taticeron18@gmail.com

Popayán-Cauca, Colombia

() RECIAMUC; Editorial Saberes del Conocimiento, 2020 


\section{RESUMEN}

Los abscesos abdominales se definen como colecciones localizadas que presentan pus, gérmenes en el frotis o crecen en el cultivo. Estas adquieren importancia cuando se hacen sintomáticas. En el manejo actual, el drenaje percutáneo es el tratamiento de elección por múltiples ventajas, reservándose el drenaje quirúrgico para ciertos casos. En la actualidad el uso de la ecografía en el drenaje percutáneo abarca el diagnóstico, el tratamiento y el seguimiento de colecciones abdominales, siendo una de los estudios más usados por sus múltiples ventajas. El objetivo fundamental de la presente investigación consiste en plasmar la utilidad de la ecografía en el drenaje percutáneo de colecciones abdominales. El diseño de investigación que se llevó a cabo es de tipo documental o bibliográfico. Entre las numerosas ventajas de la ecografía se encuentran que no es una técnica invasiva, no requiere contraste, no emite radiación por lo cual puede realizarse las veces que sea necesario, son económicas, el equipo es liviano y permite una excelente visualización de tejidos blandos y diferenciación entre sólidos y líquidos. Como todo estudio presenta sus desventajas, sin embargo, estas no superan a los beneficios que brinda. La ecografía usada en drenaje percutáneo permite realizar la guía para la punción por medio de la cual se llevará a cabo el diagnóstico y tratamiento de abscesos, asimismo la ecografía se usa durante los cuidados diarios después del procedimiento. Constituye en la actualidad una de los estudios de imagenología más usados en todo el mundo por su comprobada eficiencia y efectividad en el drenaje percutáneo y otros múltiples usos.

Palabras clave: Utilidad, Ecografía, Drenaje, Percutáneo, Absceso.

ABSTRACT

Abdominal abscesses are defined as localized collections that present pus, germs on the smear, or grow on culture. These become important when they become symptomatic. In current management, percutaneous drainage is the treatment of choice due to multiple advantages, reserving surgical drainage for certain cases. Currently, the use of ultrasound in percutaneous drainage encompasses the diagnosis, treatment and monitoring of abdominal collections, being one of the most used studies due to its multiple advantages. The main objective of this research is to show the usefulness of ultrasound in the percutaneous drainage of abdominal collections. The research design that was carried out is documentary or bibliographic. Among the many advantages of ultrasound are that it is not an invasive technique, it does not require contrast, it does not emit radiation so it can be performed as many times as necessary, it is inexpensive, the equipment is lightweight and allows excellent visualization of soft tissues and differentiation between solids and liquids. As every study has its disadvantages, however, these do not outweigh the benefits it provides. The ultrasound used in percutaneous drainage allows to carry out the guide for the puncture through which the diagnosis and treatment of abscesses will be carried out, likewise the ultrasound is used during the daily care after the procedure. It is currently one of the most widely used imaging studies in the world due to its proven efficiency and effectiveness in percutaneous drainage and other multiple uses.

Keywords: Utility, Ultrasound, Drainage, Percutaneous, Abscess.

\section{RESUMO}

Abcessos abdominais são definidos como coleções localizadas que apresentam pus, germes no esfregaço ou crescem na cultura. Estes se tornam importantes quando se tornam sintomáticos. No manejo atual, a drenagem percutânea é o tratamento de escolha devido às múltiplas vantagens, reservando a drenagem cirúrgica para alguns casos. Atualmente, a utilização do ultrassom na drenagem percutânea abrange o diagnóstico, o tratamento e o acompanhamento das coleções abdominais, sendo um dos estudos mais utilizados devido às suas múltiplas vantagens. O objetivo principal desta pesquisa é mostrar a utilidade do ultrassom na drenagem percutânea de coleções abdominais. O desenho de pesquisa realizado é documental ou bibliográfico. Entre as muitas vantagens do ultrassom, está o fato de não ser uma técnica invasiva, não necessitar de contraste, não emitir radiação, por isso pode ser realizada quantas vezes for necessário, é barato, o equipamento é leve e permite excelente visualização de tecidos moles e diferenciação entre sólidos e líquidos. Como todo estudo tem suas desvantagens, elas não superam os benefícios que oferece. O ultrassom utilizado na drenagem percutânea permite realizar o guia para a punção através da qual será realizado o diagnóstico e tratamento dos abscessos, da mesma forma que o ultrassom é utilizado nos cuidados diários após o procedimento. Atualmente é um dos estudos de imagem mais utilizados no mundo devido à sua comprovada eficiência e eficácia na drenagem percutânea e outros usos múltiplos.

Palavras-chave: Utilidade, Ultrassom, Drenagem, Percutânea, Abscesso. 


\section{Introducción}

En las últimas décadas, el tratamiento y manejo de los abscesos ha cambiado trascendentalmente. Anteriormente, el papel principal estaba desempeñado por la intervención quirúrgica que, en resumen, podía realizarse de dos formas: laparotomía o apertura de la cavidad abdominal. Este tipo de intervención ocasionaba al paciente un trauma quirúrgico importante de la pared, dolor posoperatorio, aumento de las estancias hospitalarias y un mayor número de complicaciones, entre los principales. Actualmente, los avances en radiología tales como: la tomografía computarizada, la ecografía o ultrasonido, los materiales nuevos de intervención y drenaje, han permitido crear y mejorar una técnica mínimamente invasiva con el propósito de tratar los abscesos de forma percutánea a través de guía de imagen.

Los abscesos intraabdominales se pueden localizar en cualquier parte del abdomen y el retroperitoneo. Generalmente, se forman luego de una intervención quirúrgica, un traumatismo o de enfermedades que implican una infección o una inflamación abdominal, en particular cuando se produce peritonitis o perforación. "Los abscesos no drenados se pueden extender hasta estructuras contiguas, erosionar vasos adyacentes (lo que causa hemorragia o trombosis), romperse hacia el peritoneo o el intestino, o formar una fístula cutánea o genitourinaria". Los abscesos subfrénicos pueden extenderse a la cavidad torácica, lo que puede causar empiema, absceso pulmonar o neumonía. Un absceso abdominal inferior puede descender hacia el muslo o la fosa perirrectal. El absceso esplénico es una causa rara de bacteriemia sostenida en la endocarditis, la cual se mantiene a pesar del tratamiento antimicrobiano apropiado. Los abscesos intraabdominales poseen una tasa de mortalidad del 10 al 40\%. En cuanto a la evolución, esta va a depender de la enfermedad o lesión primaria del paciente y de su estado médico general, más que de la localización y el carácter específicos del absceso. En cuanto al tratamiento pueden manejarse con antibióticos, conjuntamente con drenaje, ya sea mediante catéteres percutáneos o cirugía. (Ansari, 2018)

La colección intraabdominal es considerada un absceso. Los abscesos abdominales se definen como colecciones localizadas que presentan pus, gérmenes en el frotis o crecen en el cultivo. Estas adquieren importancia cuando se hacen sintomáticas. En el manejo actual, el drenaje percutáneo es el tratamiento de elección por múltiples ventajas, reservándose el drenaje quirúrgico para ciertos casos. Esto se debe al avance de la tecnología de los métodos auxiliares de diagnóstico por imágenes, especialmente la ecografía. (Navarro \& Orellano, 2019)

La ecografía es un estudio que utiliza ondas de sonido de alta frecuencia (ultrasonidos) con la que se producen imágenes de órganos internos y de otros tejidos. Este procedimiento se realiza mediante un dispositivo denominado transductor que convierte la corriente eléctrica en ondas sonoras las cuales se envían a los diferentes tejidos del organismo. Estas ondas sonoras rebotan en las estructuras del cuerpo y se reflejan en el transductor, el cual las transforma en señales eléctricas. Posteriormente, por medio de una computadora, las señales eléctricas se convierten en una imagen, la cual se visualiza en un monitor y se registra como una imagen digital de computadora. No se usan rayos $X$ para este estudio, es decir, "durante una ecografía no hay exposición a radiación. Las imágenes obtenidas con ultrasonidos se adquieren con la rapidez suficiente como para mostrar la motilidad de los órganos y de las estructuras del cuerpo en tiempo real". (Kocak, 2019)

Ramírez, Arroyave, Quilindo, Romero, \& Priarone (2019) refieren algunas estadísticas, refieren que:

Según las características de las colecciones, la efectividad del drenaje percutáneo guiado por imágenes puede llegar a estar 
entre el 80 y el $90 \%$. La tasa de recurrencia del absceso se estima en 5 a $10 \%$. La gran ventaja para el paciente es evitarle grandes cirugías con los riesgos que estas conllevan; no obstante, esta técnica no está exenta de complicaciones, como la perforación de algún vaso u órgano (5\%), las infecciones o la muerte (1\%). (p. 164)

En la actualidad el uso de la ecografía en el drenaje percutáneo abarca el diagnósti$\mathrm{co}$, el tratamiento y el seguimiento de colecciones abdominales, siendo una de los estudios más usados por sus múltiples ventajas. El objetivo fundamental del presente estudio consiste en plasmar la utilidad de la ecografía en el drenaje percutáneo de colecciones abdominales.

\section{Materiales y Métodos}

Con la finalidad de desarrollar la presente investigación se realizó una revisión documental de material bibliográfico localizado por medio de las siguientes bases de datos: Intramed, Mediagraphic, SciELO, Manuales MSD, ELSEVIER, NCBI, entre otras; así como también en páginas web del área de la salud con reconocimiento y evidencia científica internacional tales como la Organización Panamericana de la Salud y la Asociación Española de Gastroenterología. Fue indispensable el uso de computadoras personales con conexión a internet, para la localización del material digitalizado, constituyendo el principal recurso material para desarrollar la investigación.

Los descriptores de búsqueda usados fueron los siguientes: "Ecografía", "Guía ecográfica en drenaje percutáneo", "drenaje percutáneo" y "drenaje percutáneo guiado por ecografía". El material encontrado se seleccionó bajo algunos criterios de interés tales como idioma del contenido (español) y el rango de fecha de publicación (preferiblemente en los últimos diez años). En virtud de lo cual se clasifica la presente investigación como de tipo documental bibliográfica.

\section{Resultado}

El drenaje percutáneo se define como la evacuación del contenido líquido de una colección visualizada mediante ecografía (Fig. 1) O TAC. Existen diferentes modalidades de drenaje percutáneo. "La técnica es aplicable a un gran número de procesos, en situaciones clínicas de gravedad variable y en general con alternativas terapéuticas que pueden ser igualmente eficaces (farmacológicas, quirúrgicas o endoscópicas)". Se puede llevar a cabo un drenaje con la intención de solucionar un cuadro séptico o de aliviar los síntomas por ocupación. Entre las principales técnicas de drenaje percutáneo tenemos la de aspiración simple y la de colocación de catéter, asimismo, existen otros procedimientos relacionados tales como: instilación de fibrinolíticos, inyección de contraste a través del catéter, escleroterapia, inyección de escolicidas. En drenaje percutáneo se encuentra indicado en abscesos hepáticos, colecistitis aguda, bilomas y obstrucción biliar, pseudoquistes y abscesos pancreáticos, abscesos no parenquimatosos, quistes hepáticos simples, quistes hepáticos hidatídicos, entre los principales. (Domínguez \& Macías, 2018)

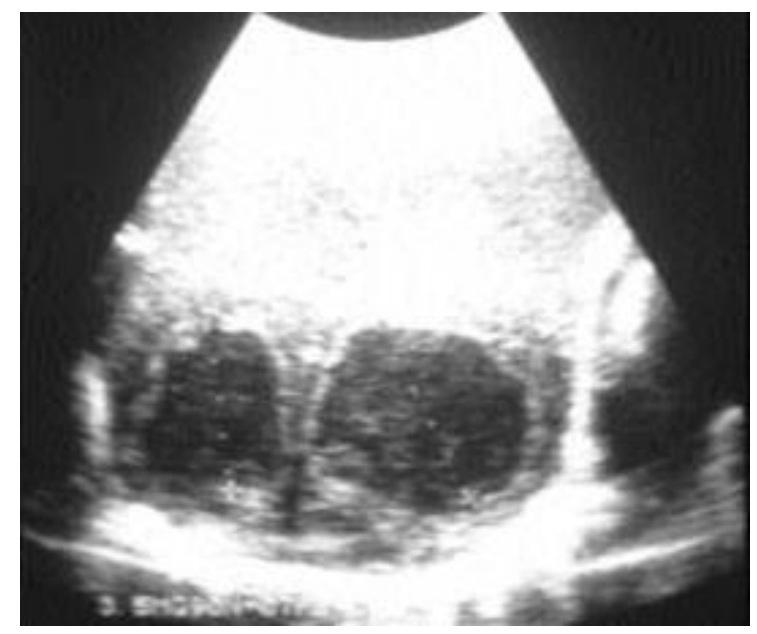

Figura 1. Visión ecográficas de abscesos hepáticos

Fuente: "Enciclopedia de Cirugía Digestiva". Giménez, M.; Donadei, G. \& Uffelmann, M. (2009). Tomo 4. p. 1. Recuperado de: https:// sacd.org.ar/wp-content/uploads/2020/05/ccuatro.pdf 
En cuanto a la ecografía, en líneas generales, existen por lo menos unas 20 especialidades donde tiene gran utilidad. Para Quintana (2014) "la ecografía por el clínico incluye 3 grandes usos: para hacer diagnóstico, para guiar procedimientos y para hacer tamización". (p. 114)

Raudales Díaz (2014) refiere al respecto que:

La ecografía a través del tiempo ha venido ganando terreno como ayuda diagnóstica de uso frecuente y confiable, hasta convertirse en el segundo método más solicitado después de los Rayos X, debido a que tiene muchas ventajas sobre la radiografía: ausencia de radiación, excelente visualización de tejidos blandos y diferenciación entre sólidos y líquidos, las ecografías pueden repetirse sin peligro alguno, son más económicas y pesan menos que un computador portátil. Estas ventajas y muchas más son al parecer, la causa del uso casi masivo de este medio diagnóstico tan útil en la actualidad. (p. 38)

Para (Cuervo, 2014) "la ecografía ofrece múltiples ventajas: puede ser hecha en la cama del paciente, no es invasiva, no requiere contraste, y no emite radiación, tiene si la desventaja de ser operador dependiente". (p. 20)

Mirpuri, Álvarez, \& Pérez (2013) refieren que "la ecografía abdominal tiene una sensibilidad de 85-95\%, sobre todo para los subfrénicos derechos, y es el método diagnóstico de elección, pero la TC tiene una mayor sensibilidad, 95-100\%, y es útil para identificar otras enfermedades asociadas". (p. 238)

En cuanto al drenaje percutáneo de colecciones abdominales guiado por ecografía es una técnica segura, fácil de realizar, con un índice de fracaso de un 17\%, en virtud de lo cual se considera un procedimiento con buen rendimiento terapéutico y baja morbimortalidad. Las ventajas de los métodos mínimo invasivos son:

- El acceso directo no contamina otras áreas

- El uso de anestesia local

- Muy buena tolerancia del paciente

- Evitar nuevas incisiones o relaparotomías

- Menor riesgo para el paciente

- Manejo de enfermería es sencillo

- Tiempo de internación reducido

- Menor dolor

- Mejor relación costo beneficio. (Vergara, Da Silva, \& Rodríguez, 2015, p. 25)

Entre las principales desventajas de la ecografía se encuentran:

- La inserción del transductor en el cuerpo puede causar alguna molestia. Rara vez, cuando se introduce un transductor, se lesiona algún tejido, lo que causa hemorragia o infección.

- El hueso o el gas pueden bloquear la ecografía. Por lo tanto, es difícil obtener imágenes de ciertas estructuras (las que están detrás de hueso o gas). (Kocak, 2019)

Asimismo, Giménez, Donadei, \& Uffelmann (2009) acerca de las desventajas de la ecografía en comparación con la tomografía, refiere que el entrenamiento es difícil y más costoso. (p. 2)

A continuación, mencionaremos las generalidades para el procedimiento de drenaje percutáneo de colecciones abdominales, con énfasis en el procedimiento para la guía ecográfica de la punción:

- Preparación previa al drenaje.

- Elección de la vía de punción: Se utilizan en general dos métodos de diagnóstico por imágenes como guía de punción de colecciones abdominales: la ecografía y la tomografía computada. La elección de una u otra se basa en la región a drenar, la disponibilidad de equipos y la ex- 
periencia del operador. Con la guía ecográfica los drenajes se pueden realizar de dos maneras:

- Guía indirecta: se localiza la colección, se elige el trayecto a recorrer y se mide la profundidad que debe alcanzar la aguja.

- En tiempo real: permite la visión continua de la aguja durante la punción. En esta técnica, con una mano se sostiene el transductor ecográfico y con la otra mano se maneja la aguja de punción, técnica ecográfica bimanual (Fig. 2). Existen dispositivos que se adosan al transductor ecográficos, en los que se monta la aguja, a fin de facilitar la visualización de la misma.

- Técnica de drenaje

- Selección del catéter

- Manejo inmediato de la cavidad del absceso

- Manejo diario del paciente con un drenaje

- Retiro del catéter. (Giménez, Donadei, \& Uffelmann, 2009, p. 2)

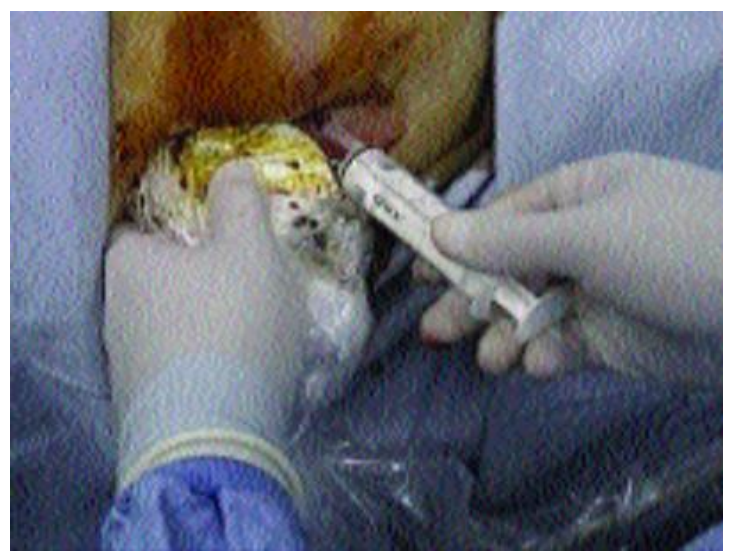

Figura 1. Técnica bimanual: exploración ecográfica y punción. Recuperado de: "Enciclopedia de Cirugía Digestiva".

Fuente: Giménez, M.; Donadei, G. \& Uffelmann, M.. (2009). Tomo 4. p. 4. Recuperado de: https://sacd.org.ar/wp-content/uploads/2020/05/ ccuatro.pdftro.pdf
En un estudio para describir la experiencia en el manejo percutáneo de colecciones abdominales en pacientes del Hospital Universitario San José de Popayán, Colombia, entre octubre de 2014 y abril de 2016, se corroboró lo siguiente:

La eficacia y la seguridad del drenaje percutáneo guiado por imágenes, con una tasa de éxito del $99 \%$ y una tasa de complicación de 1,9\%. Otro tópico a favor de la seguridad del procedimiento, es que el $100 \%$ de los drenajes se hicieron bajo sedación y los pacientes no tuvieron que ser sometidos a anestesia general y asistencia respiratoria mecánica. (Ramírez, Arroyave, Quilindo, Romero, \& Priarone, 2019, p. 168)

Por otra parte, Latorre, Lesta, \& Sainz (2019) en su investigación por demostrar la efectividad del drenaje percutáneo guiado mediante técnicas de imagen como tratamiento de los abscesos abdominales posquirúrgicos, en pacientes que presentaron un absceso abdominal como complicación tras una cirugía abdominal y que posteriormente fueron drenados por el servicio de Radiología Intervencionista del Hospital Clínico Universitario Lozano Blesa de Zaragoza (HCULB), España, desde enero del 2008 a enero del 2018, concluyeron: "El presente trabajo establece que el tratamiento de elección de abscesos intraperitoneales causados por una cirugía previa abdominal es el drenaje percutáneo guiado mediante imagen, siendo la ecografía la más utilizada". (p. 66)

Vergara, Da Silva, \& Rodríguez (2015) en su estudio para demostrar la factibilidad del manejo percutáneo de colecciones intra-abdominales en un hospital periférico de baja complejidad y con disponibilidad de ecógrafo pacientes con diagnóstico de colección intra-abdominal de distintas etiologías, internados en el Servicio de Cirugía del Hospital Distrital de Villa Elisa, Paraguay, desde junio de 2014 hasta setiembre de 2015, concluyeron lo siguiente: "Es factible el tratamiento de colecciones intraabdominales de forma percutánea en Centros

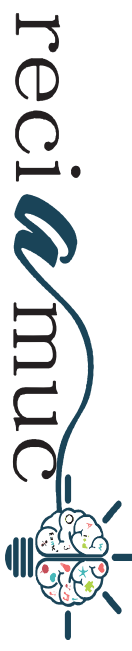


Hospitalarios periféricos que cuenten con ecógrafos y personal capacitado". (p. 27)

Los cuidados del drenaje percutáneo incluyen el uso de la ecografía, donde entre las principales recomendaciones se encuentra realizar revisiones con periodicidad variable, habitualmente 2-3 veces semanales con ecografía hasta la resolución del proceso. (Domínguez \& Macías, 2018)

\section{Conclusión}

En conclusión, es ampliamente demostrado en la literatura revisada que las técnicas intervencionistas o percutáneas resultan eficaces y seguras en manos de cirujanos debidamente entrenados, a los fines del tratamiento de las diferentes colecciones intraabdominales. En cuyo caso, la cirugía abierta estaría reservada exclusivamente para aquellos casos en los que se encuentre contraindicado el drenaje percutáneo o haya sido insatisfactorio.

La ecografía usada en drenaje percutáneo permite realizar la guía para la punción por medio de la cual se llevará a cabo el diagnóstico y tratamiento de abscesos, asimismo la ecografía se usa durante los cuidados diarios después del procedimiento. Constituye en la actualidad una de los estudios de imagenología más usados en todo el mundo por su comprobada eficiencia y efectividad en el drenaje percutáneo y otros múltiples usos.

Entre las numerosas ventajas de la ecografía se encuentran: no es invasiva, no requiere contraste, no emite radiación por lo cual puede realizarse las veces que sea necesario, son económicas, el equipo es liviano y permite una excelente visualización de tejidos blandos y diferenciación entre sólidos y líquidos. Como todo estudio presenta sus desventajas, sin embargo, estas no superan a los beneficios que brinda, razón por la cual es el segundo estudio de imágenes en todo el mundo, más usado, después de los rayos $x$.
Por último, es importante destacar que para el logro de buenos resultados en el procedimiento de drenaje percutáneo guiado por ecografía resulta fundamental el íntegro conocimiento de la patología existente, de las la técnicas a usar y todos los aspectos relativos a la imagenología. Estos aspectos no solo elevan la posibilidad de éxito, sino que también reduce considerablemente los riesgos.

\section{Bibliografía}

Ansari, P. (Diciembre de 2018). Manuales MSD. Recuperado el 05 de Agosto de 2020, de https:// www.msdmanuals.com/es-ve/professional/trastornos-gastrointestinales/abdomen-agudo-y-gastroenterolog\%C3\%ADa-quir\%C3\%BArgica/abscesos-intraabdominales

Cuervo, J. L. (2014). Apendicitis aguda. Revista hospital de niños, 56(252), 15-31. Recuperado el 21 de Agosto de 2020, de http://revistapediatria.com. ar/wp-content/uploads/2014/04/15-31-Apendicitis. pdf

Domínguez, A. A., \& Macías, M. A. (2018). Actuación de Enfermería en el Drenaje Percutáneo de Colecciones Abdominales de Patologías Digestivas. Hospital Universitario Puerta del Mar. Cádiz. Cádiz: Asociación Española de Gastroenterología. Recuperado el 08 de Agosto de 2020, de https:// www.aegastro.es/sites/default/files/recursos_enfermeria/18_PE_Drenaje_por_ecografia.pdf

Giménez, M. E., Donadei, G., \& Uffelmann, M. (2009). Absceso Hepático. En F. Galido, Enciclopedia de Cirugía Digestiva (Vol. 4, págs. 1-8). Sociedad Argentina de Cirugía Digestiva. Recuperado el 08 de Agosto de 2020, de https://sacd.org.ar/wp-content/uploads/2020/05/ccuatro.pdf

Kocak, M. (2019). Manuales MSD. Recuperado el 03 de Agosto de 2020, de https://www.msdmanuals.com/es/hogar/temas-especiales/pruebas-de-diagn\%C3\%B3stico-por-la-imagen-habituales/ecograf\%C3\%ADa

Latorre, R., Lesta, M., \& Sainz, I. (2019). Tratamiento percutáneo de abscesos posquirúrgicos. Intervencionismo, 19(2), 60-66. Recuperado el 10 de Agosto de 2020, de http://revistaintervencionismo. com/wp-content/uploads/2019_02_original2.pdf

Mirpuri, P., Álvarez, M., \& Pérez, A. (2013). Absceso subfrénico en el contexto de lumbalgia y lectura analítica en la consulta de atención primaria. Sociedad Española de Médicos de Atención Primaria - SEMERGEN, 39(4), 236-239. Recupe- 
rado el 21 de Agosto de 2020, de https://www. elsevier.es/es-revista-medicina-familia-semergen-40-pdf-S113835931200086X

Navarro, A., \& Orellano, A. (02 de Agosto de 2019). Organización Panamericana de la Salud (OPS). (R. L. (RELACSIS), Editor) Recuperado el 04 de Agosto de 2020, de https://www.paho.org/relacsis/ index.php/en/foros-relacsis/foro-becker-fci-oms/ item/998-codificacion-de-colecciones-intraabdominales

Quintana, J. E. (2014). Aplicaciones de la ecografía perioperatoria y de cuidado crítico. Revista Colombiana de Anestesiología, 42(2), 114-116. Recuperado el 15 de Agosto de 2020, de $\quad$ https://reader.elsevier.com/reader/sd/pii/ S0120334714000215?token=39B9CD81FDD02E461C7DA558E651B45CCE988BBD0DA663F09039CC7E4D48DFCD869952FDFB68A89C3712239BD4CE2229
Ramírez, J., Arroyave, Y., Quilindo, C., Romero, T., \& Priarone, C. (2019). Manejo del drenaje percutáneo guiado por imágenes en un hodpital de tercer nivel. Revista Colombiana de Cirugía, 34, 163-170. Recuperado el 02 de Agosto de 2020, de http:// www.scielo.org.co/pdf/rcci/v34n2/2011-7582-rcci-34-02-00163.pdf

Raudales Díaz, I. R. (2014). Imágenes diagnósticas: conceptos y generalidades. Revista Facultad de Ciencias Médicas, 11(1), 35-43. Recuperado el 20 de Agosto de 2020, de http://www.bvs.hn/RFCM/ pdf/2014/pdf/RFCMVol11-1-2014-6.pdf

Vergara, R. M., Da Silva, L. A., \& Rodríguez, A. (2015). Manejo percutáneo de colecciones abdominales en el Hospital Distrital de Villa Elisa. Cirugía Paraguaya, 39(2), 24-28. Recuperado el 19 de Agosto de 2020, de http://scielo.iics.una.py/pdf/ sopaci/v39n2/v39n2a06.pdf

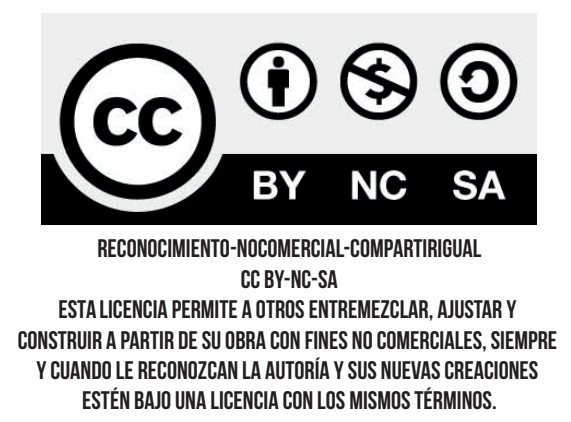

\section{CITAR ESTE ARTICULO:}

Cerón Pérez, D., Báez Quiñónez, D., Álvarez Pérez, L., \& Zambrano Palma, D. (2020). Utilidad de ecografía en drenaje percutáneo. RECIAMUC, 4(3), 208215. doi:10.26820/reciamuc/4.(3).julio.2020.208-215 